\title{
Discussion on Innovation of Construction Management and Green Construction Management
}

(Huatu Construction Group Co., Ltd , Jingmen, Hubei, 448000, China)

\section{Significance of Innovation in Construction Management}

With the continuous development of the current enterprise, the construction industry has made a very high progress. In the actual construction, having certain quality and price advantages require enterprises to strengthen innovation in management. On this basis, it is necessary to keep pace with the construction management innovation. Only by ensuring the continuous innovation of construction technology can we effectively process the problems existing in the actual development and optimize the development structure. In recent years, with the continuous development of the construction industry, the related types of projects are implemented in the city. The project construction is directly related to its surroundings, which has a direct connection with the life and work of the people, so it is necessary to strengthen the construction technology and perfect the construction technique so that it can meet the relevant standard requirements. In the project construction, due to the relatively large demand for related materials and processes and in order to be able to adapt to the current market environment, it is necessary to continuously strengthen the management of construction technology so as to effectively optimize the construction technology.

\section{Engineering Management}

\section{Residential Building Construction}

2.1 The Innovation of Management System

In the current social development, if we need to establish a system that adapts to the enterprise system, we need to strengthen the standardization of management methods. In the actual construction of the project, the project and the responsibility of the enterprise should be effectively clear and the relationship between the various departments of the project should be handled rationally, so that the problems existing in the construction management system can be effectively dealt with so as to improve engineering management and construction efficiency. Therefore, for construction enterprises, it is necessary to strengthen effective management so that enterprises can adapt to the internal control and management atmosphere of enterprises. At the same time, it can avoid the risks that exist in society, and it can reduce the risk in the operation, so that it can be in line with the requirements of the contract to effectively improve the management level.

\subsection{Innovation of Management Methods}

It is very important to innovate the management methods in the construction engineering management. Different management content has different characteristics, so enterprises need to choose scientific and reasonable
Abstract: In the construction industry, the innovation of construction management is the inexorable trend of its development. Strengthening the scientific and reasonable management method has a very important influence on the improvement of engineering quality. It not only can control the cost well, but also can promote the economic benefit of the enterprise, which has a good promotion effect on the shortening of the construction period. Under the current concept of sustainable development, adopting the innovation of construction management and strengthening the importance of the green construction concept are necessary to adapt to the development needs of the society. This paper mainly analyzes and discusses the construction management innovation and green construction management.

Key words: Construction management; Innovation; Green construction management

Published online: $30^{\text {th }}$ Nov, 2017 
management modes. First, to strengthen the innovation of construction technology management. This is mainly because its own technology is very strong in the building construction. On this basis, it is necessary to strengthen the effective understanding on construction technology and related construction equipment, and also need to pay more attention to the management of construction technology. Construction enterprises need to continuously strengthen the effective training and assessment of personnel, and do a good job of corresponding technical supervision and management. In this case, the corresponding construction plan needs to be done to effectively integrate the equipment into the engineering construction and strengthen the continuous innovation of technical management in the whole. Second, to strengthen the innovation of human resource management methods. In this process, construction enterprises need to improve the mechanism of personnel training and establish corresponding responsibility system and assessment system, etc. For different positions, in order to improve the efficiency of management, we should strengthen the orderly development of human resources.

\subsection{Innovation of Management Means}

As far as construction enterprises are concerned, construction management is a systematic engineering, which not only has a direct connection with a lot of information storage and management, but also has a great influence on each link. This requires more innovation in management.By using information technology to effectively construct the project management system, the management links of financial management, cost management, schedule and quality are effectively connected, so that information can be shared and circulated and information can be realized effectively to improve the quality of management and efficiency.

\section{Construction Management Method of Green Building}

3.1 Save Construction Materials and Reduce Energy Consumption
First, it is necessary to rationally allocate resources according to actual planning and construction requirements, in which mainly are construction materials, machinery and equipment and personnel. On the basis of ensuring the quality of the project, ensure that the materials consumption is reduced. For example, for some construction machinery, it is usually necessary to apply some equipment with higher construction efficiency and lower resource consumption. At the same time, it is necessary to strengthen the retrofit of some equipment with higher consumption, and to strengthen the replacement when necessary, which is scientific and reasonable so as to ensure the smooth implementation of the construction.

\subsection{Avoid Environmental Pollution}

In the actual construction, the building will produce the corresponding wastes such as slag and some old decorative materials, etc. In a sense, it will not only take up a lot of land area, but also affect soil fertility. It is difficult to ensure that crops can be grown. In addition, there are heavy metals in some wastes, which can be infiltrated underground by rain during the rainy season, causing pollution to groundwater and having a great impact on people's living environment. In addition to being able to use the amount of waste generated during construction as the beam bottom, adopting green building management can also reduce its environmental hazards.

\subsection{Control Noise and Bright Light}

The pollution caused by noise has a direct impact on the life of people around them, and it will harm the health of the workers in the construction site. Because of the long-term environment, it is easy for people to have hearing impairment. Using green construction management, the construction enterprises can plan the construction time reasonably to prevent the effect of the construction at night on the people due to the emphasis on the construction period. At the same time, the new sound insulation materials can be used to protect the construction site so as to obtain the effect of noise absorption. If it is necessary to carry out overtime work at night, it will generally be constructed by using some lighting with relatively high light intensity. Therefore, these lights usually have an impact on the life of residents in the neighborhood. To strengthen the management of green building construction, we can implement the corresponding enclosure at the construction site, or adopt some energy-saving light sources with divergent types. Due to the relatively short distance of propagation of such a light source itself, it will not have a certain impact on the life of the residents outside the construction envelope.

\subsection{Material Recovery and Utilization}

In the actual construction of buildings, as far as possible to adopt energy-saving environmental protection materials. In this way, either the engineering waste or the material after the demolition of the building can be used for recycling or reprocessing. It not only can reduce the pollution to the surrounding environment, but also reduce the construction cost in a certain sense and increase the economic benefit of the enterprise.

\section{Conclusion}

The green construction management mode is the inevitable trend in the development of the construction enterprise. However, whether it is effective or not requires the construction enterprises to demand themselves according to the corresponding green management concepts and take the market change as the basic criterion to achieve green management in all aspects. In this way, enterprises can achieve continuous development.

\section{References}

[1]Zhuang Bingcong. Exploration of construction management innovation and green construction management [J]. Jiang Xi Jian Cai, 2016, (22):291.

[2]Yang Yanli. How to innovate construction management under the concept of green construction management [J].SME Management and Technology (Mid-term), 2014, (05):58-59. 